\title{
A DIMENSÃO DO EXCESSO: BATAILLE E FREUD
}

\author{
Isabel Fortes
}

Professora visitante do Programa de Pós-Graduação em Teoria Psicanalítica do Instituto de Psicologia da UFRJ, membro do Espaço Brasileiro de Estudos Psicanalíticos.
RESUMO: Aproxima-se a teoria freudiana da obra de Bataille, cujo pensamento traz considerações importantes para a dimensão econômica de Freud. Sugere-se que essa correlação pode ser feita por meio do termo pressão, presente nos dois autores. O argumento principal do artigo é a ideia de que há uma pressão permanente provinda de um excesso que perturba os organismos vivos, havendo então a exigência do desperdício, do gasto ou da descarga. No caso da psicanálise, esse dispêndio ocorre sob a forma da dominação dos estímulos, principal função do aparelho psíquico, seja essa realizada pela descarga energética, seja pela elaboração psíquica.

Palavras-chave: Excesso, desperdício, pulsão, Freud, Bataille.

ABSTRACT: The dimension of the excess: Bataille and Freud. Freudian theories are linked to Bataille's work, whose thought brings important considerations for the economical Freudian dimension. The intention is that this correlation can be made through the term pressure, present in both authors. The main argument of the article is that there is a permanent pressure originated from an excess which bothers the living organisms, therefore resulting in the demand of the waste, the use and the discharge. In respect to psychoanalysis, this ravage occurs under the form of stimuli domination, the main function of the psychic apparatus, whether it is done through the discharge of energy, whether it is done by psychic elaboration.

Keywords: Excess, waste, instinct, Freud, Bataille. 


\section{INTRODUÇÃO}

Estudaremos aqui a noção de excesso nas teorizações do filósofo francês Georges Bataille, particularmente a partir do livro A parte maldita (1949/1975) e do artigo “A noção de despesa”, de 1933, que o precedeu, levando em conta os 16 anos de intervalo entre os dois trabalhos. Pensador que levou a filosofia a exceder seus próprios limites, Bataille notabilizou-se pelo desafio de tornar pensável o impossível, de propor questões filosóficas acerca daquilo que se encontra nas bordas do pensamento, assim como nas bordas da própria vida. Tendo tal tarefa em mente, o autor adentrou os campos sinuosos do excedente, do erotismo, da morte, da transgressão, do êxtase, do sagrado, da dor e do sacrifício, buscando demonstrar que é na violência que o homem potencialmente se revela.

Nossa proposta é articular o pensamento de Bataille com as teorizações freudianas, apostando em um diálogo fecundo entre os dois autores, que, a nosso ver, pode realizar-se por meio da noção batailliana de gasto excedente e do ponto de vista econômico na obra freudiana, mais marcadamente do destino do excesso pulsional.

Diante de tal circunscrição do problema, escolhemos nos debruçar sobre o livro A parte maldita, pelo fato de este explorar os rumos que um sistema, seja este uma sociedade ou um indivíduo, pode fornecer para o excesso que lhe é inerente. Com efeito, essa obra aproxima a ordem social ao campo do sujeito, estando aí em jogo o funcionamento do organismo vivo. As questões acerca da energia excedente no globo terrestre podem ser apropriadas para refletirmos sobre a ordem individual, sendo esta última também acometida por um 'estado de ebulição': "Com efeito, a ebulição que tenho em vista, a ebulição que anima o globo, é também minha ebulição. Assim, esse objeto de minha pesquisa não pode ser distinguido do próprio sujeito, mas devo ser mais preciso: do sujeito em seu ponto de ebulição" (Idem, p.50).

Esse ponto é particularmente importante para a correlação que queremos fazer entre os dois autores, pois inferir que a ebulição do globo terrestre é equivalente à efervescência do sujeito oferece o gancho para aproximar, como o faremos mais adiante, a noção de desperdício do modelo da descarga energética pressuposto no aparelho psíquico freudiano. A 'economia generalizada' de Bataille oferece, assim, um chão teórico profícuo para a associação entre as formas dadas ao excedente pela economia global e o aspecto econômico em Freud, mais especificamente ao destino do excesso pulsional no psiquismo humano.

\section{PRESSÃO E PERDA DO EXCEDENTE}

A parte maldita versa sobre economia, mas não sobre uma economia convencional, e sim o que o autor denomina 'economia generalizada'. Esta última reivindica que um sacrifício humano, a construção de uma igreja ou o presente de uma 
joia são tão importantes quanto a venda do trigo. Todo o problema reside em saber como, no seio dessa economia geral, é usado o excedente. O título do livro indica que há uma espécie de maldição em jogo neste domínio. A energia excedente constituir-se-á em uma "parte maldita”, já que não será utilizada para o crescimento ou para a conservação dos sistemas. Trata-se de uma maldição pelo fato de o dispêndio ser exigência da própria sobrevivência do sistema. É peremptório perder o excedente, seja essa perda realizada de boa vontade ou não, gloriosamente ou de modo catastrófico.

O desenvolvimento teórico desse tipo de economia reivindica que o gasto e o consumo consistem em elementos mais fundamentais que a produção, tendo aqueles uma anterioridade em relação a esta última. Há assim um caráter secundário da produção em relação ao gasto e ao consumo, ocorrendo uma inversão do modo tradicional de compreensão da troca:

“A troca (...) apresenta-se assim, basicamente, como um processo de despesa sobre o qual se desenvolveu um processo de aquisição, a afirmação do caráter secundário da produção e da aquisição em relação à despesa: a ideia de um 'mundo pacífico e conforme a seu modo de ver', que seria ordenado pela necessidade primordial de adquirir, de produzir e conservar, é apenas uma 'ilusão cômoda', quando o mundo em que vivemos está consagrado à perda e quando a própria sobrevivência das sociedades só é possível ao preço de despesas improdutivas consideráveis e crescentes." (Idem, p.16)

Assim, o consumo é visto como necessário, constituindo-se em desperdício da energia excedente que existe em qualquer sistema. O autor refere-se aqui, de maneira mais específica, ao excedente encontrado nos movimentos da superfície do globo terrestre. O organismo vivo recebe, em princípio, mais energia do que é necessário para a manutenção da vida. Os estudos sobre a biosfera indicam que a esfera terrestre apresenta um volume total no qual o espaço demarcado para acolher a energia é limitado. O crescimento terá um ponto a partir do qual ele cessa; não há crescimento ilimitado.

Bataille atribui aos seus estudos em conjunto com o físico Georges Ambrosino a possibilidade de desenvolver estas formulações, chegando a lhe dedicar este livro ao dizer que sem o amigo "não teria podido construir esta obra” (Idem, p.53).

Dessa forma, a ideia geral é que há um limite para que a energia seja utilizada para o crescimento do sistema. As modalidades de crescimento da vida vão sempre se chocar com barreiras. Se certa porção da energia é dirigida ao crescimento, à produção e à conservação, outra parte permanece como excedente, sendo necessária sua consumição. É utilizada aqui a imagem da exuberância do sol, pois a fonte de nossa riqueza é dada pela energia solar, que fornece calor sem solicitar 
contrapartida: “o sol dá sem nunca receber" (Idem, p.66). A irradiação solar terá então como efeito a superabundância da energia na superfície do globo. O organismo vivo recebe esta energia e a distribui dentro dos limites do espaço disponível, remanejando-a ao máximo para o crescimento.

Desse modo, há uma pressão que age permanentemente sobre os organismos vivos, efeito do excedente de energia que não tem como ser usada em prol do crescimento. A pressão está sempre lá, levando a vida a dilapidar os recursos excedentes. Quando se atinge o máximo do crescimento, a vida entra em ebulição: "sem explodir, sua extrema exuberância corre em um movimento sempre próximo da explosão” (Idem, p.68). Entra aqui em vigor o princípio da perda: se não há mais como utilizar esta energia, só resta ao organismo despendê-la: “essa perda inevitável não pode de forma alguma passar por útil” (Idem, p.69). A questão passa a se concentrar então na maneira de perder o excedente: "tratase de consentimento, e não mais de utilidade. Essas consequências, no entanto, são decisivas” (Idem, p.69). Assim, há que se consentir à inevitabilidade da perda e, ao fazê-lo, esta pode tornar-se uma experiência não tão desagradável. É necessário perder a energia em acréscimo, vivida pelo organismo vivo como sendo um excesso.

Portanto, a pressão tem como um de seus possíveis efeitos o luxo ou a dilapidação, que podem conduzir à extinção de possibilidades, mas podem também levar à abertura de um novo espaço.

É importante ressaltar que a exigência de perda está também presente na noção batailliana de erotismo, que requer a destruição do objeto-coisa em que se tornou o homem devido à sua entrada no mundo do trabalho. O erotismo é um movimento de violência, na medida que é necessário eliminar a ilusão da duração criada pelo trabalho, a fim de adentrar a consecução erótica (BATAILLE, 1957/1980).

A ideia da dilapidação dos bens fora trabalhada por Bataille em um ensaio que havia escrito muitos anos antes de A parte maldita. No artigo "A noção de despesa", de 1933, vê-se que existe nos grupos sociais, em permanente estado endêmico, uma pressão que conduz ao princípio da perda.

Este ensaio foi resultante do impacto que a obra de Marcel Mauss exerceu sobre Bataille. O conhecimento da teoria do potlatch exposta pelo sociólogo francês em “Ensaio sobre a dádiva: forma e razão da troca nas sociedades arcaicas" (1924) parece estar na origem do extremo interesse que Bataille passou a demonstrar, logo em seguida a essa leitura, pelos fatos econômicos.

Dessa maneira, o ensaio propõe que a noção de gasto improdutivo indica um modo de atividade econômica que se opõe ao princípio da utilidade clássica. Se para a utilidade o importante é a aquisição e conservação dos bens, reprodução e conservação da vida, constata-se que há um domínio da sociedade humana que 
visa a perda e a dilapidação dos bens. Não parece ser possível para o domínio da utilidade conceber "que uma sociedade humana possa ter interesse em perdas consideráveis, em catástrofes que provoquem, de acordo com necessidades definidas, depressões tumultuosas, crises de angústia e, em última análise, um certo estado orgíaco" (BATAILLE, 1949/1975, p.28).

Existe, portanto, uma contradição entre as concepções sociais clássicas e as necessidades reais da sociedade, na qual se encontra permanentemente, em estado endêmico, a exigência da despesa.

O princípio da perda reivindica que o consumo pode ser tanto para o uso da energia necessária para a conservação da vida e da espécie como também para as despesas improdutivas, motor primeiro das instituições econômicas. Esse modo de desperdício aparece nas festas, no luxo, nas guerras, nos jogos, nos enterros, nos espetáculos e em várias outras atividades da vida social.

Mesmo diante do horror que constitui a miséria humana, essa não faz com que a preocupação com a conservação prevaleça sobre o desperdício. A economia clássica não pôde supor que a troca tivesse como causa não a necessidade de adquirir, mas, ao contrário, a exigência de destruição e perda. As concepções econômicas desenvolvidas por Bataille são, portanto, uma espécie de inversão do pensamento econômico comum, pois a dimensão do luxo está presente nas trocas, que não são exclusivamente regidas pelo domínio da necessidade: "Não é a necessidade, mas seu contrário, o 'luxo’, que coloca para a matéria viva e para o homem seus problemas fundamentais" (Idem, p.51).

\section{A DÁDIVA COMO TROCA AGONÍSTICA DOS BENS}

A concepção da despesa como o motor primeiro da economia aparece de maneira mais evidente em algumas sociedades arcaicas. O potlatch, modo de troca presente em certas sociedades estudadas pelas pesquisas antropológicas, consiste em dádivas ostentatórias de riquezas oferecidas pelos chefes das tribos com a finalidade de humilhar, de desafiar e de obrigar um rival. O potlatch não acontece exclusivamente por meio de presentes, mas também pode ocorrer por destruições espetaculares da própria riqueza. Há exemplos de destruições suntuárias de escravos, cachorros, incêndios de aldeias e afundamento de canoas. O princípio da perda visa à aquisição da honra, glória ou posição na hierarquia, ou seja, a perda material pode se transformar em ganho no nível imaterial. O poder de um chefe passará então a ser significado a partir de seu poder de perder:

“a riqueza aparece como aquisição enquanto um poder é adquirido pelo homem rico, mas ela é inteiramente dirigida para a perda, no sentido em que esse poder é caracterizado como poder de perder. É somente pela perda que a glória e a honra lhe são vinculadas." (Idem, p.36) 
Como salienta Caillé (1998), há na concepção da dádiva um antiutilitarismo por excelência, pois nenhuma sociedade humana pode edificar-se exclusivamente sob os registros do contrato e do utilitário, existindo sempre uma zona que escapa a estes registros. No entanto, o autor mostra que o ineditismo da teoria de Marcel Mauss não está somente em afirmar que a ordem social é irredutível à ordem econômica utilitária. Este postulado não chega a ser uma novidade, pois o encontramos na sociologia clássica em autores como Weber, Simmel e Tocqueville. O ineditismo do paradigma da dádiva estaria no fato de propor um “antiutilitarismo positivo” (CAILLÉ, 1998). Quando as sociologias clássicas reivindicam um antiutilitarismo, é sempre sob um viés negativo. No entanto, a dádiva traria consigo a perspectiva de uma crítica ao utilitarismo, mas o faz de forma positiva, ao fornecer como alternativa a ele os fundamentos de uma ordem social outra. Por isso, além do holismo ou do individualismo, o paradigma da dádiva seria uma terceira via para pensar a ordem social, pois se distinguiria tanto da ordem do cálculo egoísta característica do individualismo, como do caráter de benevolência aos costumes e regras sociais inerente ao universo holista. A dádiva não se incluiria em nenhuma dessas duas propostas, pois apostaria em um modo de aliança em que é possível a generosidade mesmo diante do adversário.

Portanto, se há na dádiva alguma espécie de ganho, este ocorrerá posteriormente, e não como um elemento que aparece de antemão, como pretende o utilitarismo. O potlatch inclui a dimensão do risco, pois se trata de uma luta que possui a perda como aspecto crucial do combate.

Mauss (1924/1950) denominou potlatch (termo que na língua corrente dos índios de Vancouver significa alimentar, consumir) o sistema de prestações totais do tipo agonístico, no qual se encontram os traços de desafio, luta e humilhação. O que há de mais notável aí é o princípio de rivalidade e antagonismo que domina essas práticas.

Mas por que esse modo de prestação foi chamado de "sistema de prestações totais"?

O termo "prestação" compreende "um contrato para prestar uma coisa ou um serviço” (MAUSS apud GODELIER,1998). Há os contratos de prestação total e aqueles em que a prestação é apenas parcial. Os de prestação total podem ser de duas categorias, dependendo se os dons e contradons trocados assumem uma forma antagonista ou não. A forma antagonista surgiu mais tarde no curso da história e culminou no potlatch. São precisamente esses dois modos de prestação - não-antagonistas e antagonistas - que serão chamados de "sistema de prestações totais". A prestação é caracterizada como total quando o que se troca não são somente bens e riquezas, mas vários elementos da vida social e institucional: 
"O que eles trocam, não são exclusivamente bens e riquezas, móveis e imóveis, coisas economicamente úteis. São, sobretudo, cortesias, festas, ritos, serviços militares, mulheres, crianças, danças, feiras, nos quais o mercado é apenas um momento e a circulação de riquezas somente um dos termos de um contrato mais geral e mais permanente.” (MAUSS, 1924/1950, p.63)

Portanto, as prestações são consideradas totais no sentido de abrangerem ao mesmo tempo os fenômenos jurídicos, religiosos, mitológicos, xamanistas ou estéticos. Nessa prática agregam-se muitos aspectos da vida social e diversas instituições que caracterizam uma sociedade.

Godelier (1998) salienta que a forma agonística do dom foi a única trabalhada por Mauss. A forma não-antagonista foi mencionada em seu ensaio, mas não chegou a ser desenvolvida: "O que fascinava Mauss eram os dons em que predominavam a rivalidade, a competição e o antagonismo (...). Portanto, ele fez do potlatch uma categoria sociológica geral e é sob este selo que os dons agonísticos tornaram-se conhecidos e foram popularizados” (p.87). Por isso, o verdadeiro potlatch é aquele que torna impossível a retribuição, ou seja, essa prática social recebe a sua melhor forma quando a dádiva adquire uma força em face da qual não é possível a retribuição por parte do adversário:

“No potlatch se dá alguma coisa para 'esmagar' o outro com este dom. Por isso se dá mais do (do que se pensa) que ele poderia restituir ou se restitui muito mais do que aquilo que ele deu. Como com os dons e contradons não-agonísticos, o dompotlatch endivida e obriga aquele que o recebe, mas o objetivo visado é explicitamente tornar muito difícil, se não impossível, o retorno de um dom equivalente: trata-se de colocar o outro em dívida de modo quase permanente, de fazer com que perca seu prestígio publicamente, de afirmar assim, pelo máximo de tempo possível, a própria superioridade.” (GODELIER, 1998, p.88)

O traço da obrigação que é contraída por meio da dádiva é um aspecto fundamental. Estas prestações são realizadas por meio de presentes que implicam uma obrigação para o donatário: “Estas prestações e contraprestações eram acertadas de uma maneira voluntária, através de dádivas, presentes, embora fossem, no fundo, rigorosamente obrigatórias, sob pena de guerra privada ou pública” (MAUSS, 1924/1950, p.151).

Nesse sentido, a recusa a dar, o evitamento de convidar, a negação de receber é equivalente a declarar a guerra, a mostrar-se avesso ao estabelecimento da aliança e da comunhão. Mas a dádiva não consiste exclusivamente no ato de dar, tratando-se do encadeamento de uma tripla obrigação que envolve “dar, receber e retribuir" que inclui, portanto, a obrigação da contrapartida. 
Conforme Caillé (1998), há aqui um aspecto bem paradoxal, pois se trata de uma generosidade, só que esta se constitui como obrigatória. Como indica Godelier (1998), o dom aproxima os protagonistas por ser uma forma de partilha entre eles, mas ao mesmo tempo os afasta socialmente, pois transforma um deles em devedor do outro.

Ao desenvolver este encadeamento das três obrigações, Mauss explica que isso ocorre porque existe uma circularidade entre as coisas e as pessoas, uma força única que as une em um mesmo movimento: "tudo vai e vem como se houvesse troca constante de uma matéria espiritual envolvendo coisas e homens, entre os clãs e os indivíduos, repartidos entre as categorias, os sexos e as gerações" (MAUSS,1949/1975/1950, p.164). Doa-se porque se é forçado a isso, porque o donatário tem uma espécie de direito sobre tudo o que pertence ao doador. O doador pode até ter o direito de uso, mas não possui o direito de propriedade. Essa mescla de deveres ao mesmo tempo simétricos e contrários deixa de se mostrar contraditória quando se percebe que há ligações espirituais entre as coisas e os indivíduos e grupos.

Diversas regras e ideias se inserem nesse modo de direito e economia. A mais importante delas, segundo Mauss (1924/1950), é aquela que obriga a retribuir o presente recebido. No estudo que o antropólogo realizou com as tribos da Polinésia, vê-se a presença dessa força que exige a retribuição de algo recebido:

“Dois elementos essenciais do potlatch propriamente dito são verificados: aquele da honra, do prestígio, do 'mana' que a riqueza confere, e aquele da obrigação absoluta de retribuir estes dons sob pena de perder este 'mana', esta autoridade e esta fonte de riqueza que é a autoridade ela mesma." (MAUSS, 1924/1950, p.155)

\section{PRESSÃO E DESCARGA DO EXCESSO PULSIONAL}

A aproximação entre a noção de despesa em Bataille e a dimensão do excesso em Freud sustenta-se no fato de o conceito de pulsão ter como condição a pressão. Para analisarmos a questão do excesso na obra freudiana, é necessário valorizarmos o ponto de vista econômico da metapsicologia. Se Freud apresenta o sintoma e seus efeitos tanto pela linguagem tópica como pela linguagem econômica, é a partir dessa última que a dimensão do excesso pode ser considerada.

Assim, para efetuar uma análise sobre o excesso, precisamos investigar, antes de mais nada, o conceito de pulsão, pois o excesso na teoria freudiana será sempre da ordem do pulsional. Com efeito, no ensaio "Os instintos e suas vicissitudes" (1915), Freud demonstra que a pulsão é resultante de uma força constante, uma pressão permanente que acossa o psiquismo. O aspecto da força anuncia aqui 
a dimensão do excesso inerente à pulsão, antes mesmo da elaboração sobre o excesso realizada a partir do conceito de pulsão de morte (FREUD, 1920).

No ensaio de 1915, trata-se de um excesso de estimulação proveniente do corpo que exerce uma tensão interna e visa à satisfação. Essa tensão é insistente e perturbadora, e por isso é necessário seu escoamento. Se em Bataille a energia excedente é despendida no gasto improdutivo, em Freud o excesso pulsional é conduzido para a descarga energética. A pulsão busca o escoamento da energia excedente para que possa alcançar a satisfação. Esta última somente ocorrerá quando houver o cessamento ou a diminuição da estimulação.

Freud inicia o seu ensaio associando à pulsão a ideia de estímulo utilizada pela fisiologia. Ao ser relacionado com a fisiologia do sistema nervoso, o aparelho psíquico freudiano é concebido a partir do modelo do arco reflexo, que compreende que um estímulo aplicado à substância nervosa a partir do mundo exterior será descarregado para fora, por meio de uma ação. O esquema da ação reflexa é paradigmático para a compreensão da pulsão, pois esta exige que o psiquismo efetue a expulsão da tensão interna causada pelo impulso excessivo. No entanto, de maneira diferente do estímulo, a pulsão é efeito de uma pressão que provém de dentro do organismo.

Como a estimulação pulsional é proveniente do interior do corpo, a mais importante característica do estímulo endógeno é o fato de que não se é possível fugir dele. Assim, enquanto o estímulo fisiológico atua como uma força que imprime um impacto momentâneo no organismo, a pulsão age como um impacto constante. A força da pulsão é constante, pelo fato de vir de dentro e de não permitir a fuga.

Portanto, o modelo simples do ato reflexo se complexifica na ordem das pulsões, sendo estas últimas as responsáveis pela constituição do aparelho psíquico: “Podemos, portanto, concluir que as pulsões e não os estímulos externos constituem as verdadeiras forças motrizes por detrás dos progressos que conduziram o sistema nervoso, com sua capacidade ilimitada, a seu alto nível de desenvolvimento atual" (FREUD, 1915, p.140).

Assim, as pulsões demandam que o sistema nervoso suporte o afluxo incessante e inevitável dos estímulos, renunciando à intenção ideal de afastá-los. É exatamente esse aspecto da força na pulsão que nos leva a circunscrevê-la à dimensão do excesso.

Freud mostra que o melhor termo para definir o estímulo pulsional seria "necessidade" (Idem, p.139). Somente pela satisfação da necessidade seria possível suspender a tensão que ela gera. A pulsão exige muito mais do sistema nervoso do que a excitação fisiológica, fazendo com que sejam necessárias "atividades complexas e interligadas, pelas quais o mundo externo se modifica de forma a proporcionar satisfação à fonte interna de estimulação” (Idem, p.140). 
Desse modo, como não é possível eliminar pela ação a excitação provinda do corpo, isto é, como nenhuma fuga prevalece contra esta estimulação, faz-se necessário outro procedimento para a sua regulação, o que pode ser alcançado apenas por uma alteração apropriada da fonte interna de estimulação. Por isso mesmo, este ensaio já anuncia em seu próprio título que vai tratar dos 'destinos' da pulsão, ou seja, dos caminhos que ela percorrerá para encontrar a sua regulação no psiquismo, na medida que sua eliminação pela descarga não é possível.

Tendo em vista a pressão constante, a pulsão será definida como uma exigência de trabalho, mais precisamente "uma medida da exigência feita à mente no sentido de trabalhar em consequência de sua ligação com o corpo" (Idem, p.142). Portanto, é necessário que o psiquismo trabalhe para que possa encontrar caminhos possíveis para o excesso pulsional. Trata-se de um trabalho de descarga, de escoamento, de regulação, que visa conduzir a destinos psíquicos que viabilizem manejar a intensidade da estimulação e alcançar a satisfação.

David-Ménard (2000) desenvolve essa questão, mostrando que o sintoma será visto como excesso se o ponto de vista tópico for associado ao ponto de vista econômico na análise que dele fazemos. Para se conceber as pulsões, a linguagem energética do excesso e a linguagem tópica precisam convergir. A produção sintomática pode ser considerada da ordem do excesso, pois algo de irreprimível atua no sintoma, sendo esse ‘algo’ a própria pulsão:

“A ideia de que algo de irreprimível se afirma e se manifesta no sintoma (...), sem que o sujeito em questão saiba de que se trata e sem que possa integrá-lo em sua vida. Este algo irreprimível que se afirma de um modo paradoxal - que ao mesmo tempo se trata de nós mesmos e, no entanto, é quase anônimo - é o que Freud denomina pulsão.” (DAVID-MÉNARD, 2000, p.14)

Com efeito, o espantoso da pulsão é o fato de nos converter em seres quase anônimos, e, não obstante, constituir a nossa singularidade. O fato de não haver fuga possível da pulsão faz dela um perigo, mas um perigo que nos constitui. Dele não conseguimos escapar, tendo que encontrar destinos possíveis, já que, como vimos, a força é constante e componente integrante do aparelho.

Nesse sentido, podemos afirmar que o aparelho psíquico tem como função primordial a dominação dos estímulos, constituindo-se como um sistema de captura do excesso pulsional. A dominação dos estímulos é, então, a via pela qual se torna possível conviver com a pressão constante, sendo a tarefa primordial do psiquismo a captura das intensidades. O termo em alemão para dominação é Reizbewältigung, que significa dominar, amansar, lidar com — essa é a principal função do aparelho psíquico face ao impacto das intensidades pulsionais. 
Birman (2009) avança ainda mais nessa proposição, ao afirmar que a própria constituição do aparelho psíquico ocorre para que o domínio das excitações pulsionais seja realizado. Face à insuficiência vital do vivente, não tendo o sistema nervoso sido capaz de dominar a contento o excesso pulsional pela descarga e pela ação reflexa, foi necessária a produção de outras operações para que as excitações pudessem ser reguladas e a tensão diminuída:

“Assim, o aparelho psíquico teria sido de fato constituído para realizar o domínio das excitações pulsionais, impossíveis de serem reguladas pelo aparelho nervoso. Seria então uma insuficiência vital, materializada no aparelho nervoso, o que teria conduzido evolutivamente o vivente à necessidade de forjar o aparelho psíquico para lidar da maneira correta com as excitações pulsionais.” (BIRMAN, 2009, p.90)

Observa-se que em 1915 aparece de maneira clara a formulação de que a função do aparelho psíquico é o domínio das excitações. No entanto, é importante lembrar que desde o "Projeto para uma psicologia científica”, de 1895, Freud postula que o aparelho psíquico deve realizar o remanejamento interno das quantidades de excitação que o assola. David-Ménard (2000) reafirma essa hipótese, sinalizando que já no Projeto de 1895 o aparelho se constitui a partir de um excesso, descrito como uma experiência de quantidade.

Com efeito, no ensaio de 1895 o psiquismo é desenvolvido a partir da regulação e da complexificação (complicationes) das quantidades brutas de excitação que nele adentram, vindas tanto a partir do mundo exterior como da vida intercelular do organismo. Por meio das marcas deixadas pelos trilhamentos pelos quais a excitação se conduz é que o sujeito se constitui.

A instância prazer-desprazer é um dos operadores da organização psíquica, responsável pela sua conservação. Seu mecanismo tem por objetivo fazer com que a quantidade dos estímulos não chegue a um grau insuportável para o organismo, cabendo, ao aparato neuronal, manter no psiquismo um nível ótimo de energia que não exceda uma determinada quantidade. Assim sendo, o psiquismo pode regular, pelo funcionamento da descarga, os excessos da excitabilidade. Esse modo de compreensão do aparato psíquico tem por premissa que o excesso é um incômodo que deve ser devidamente eliminado pelo processo da descarga, a fim de que se obtenha o prazer.

A partir dessa perspectiva, David-Ménard (2000) propõe que se conceba o aparelho psíquico como sendo eminentemente um aparelho de "prazer, desprazer e angústia”, no qual o prazer é definido como a sensação da descarga energética e a função do aparelho é a descarga. Pensar o psiquismo desse modo permite inscrevê-lo no campo das intensidades e valorizar o ponto de vista econômico da 
metapsicologia, cuja importância para a compreensão da dimensão do excesso foi apontada mais acima.

A compreensão do princípio de prazer como descarga o aproxima, inicialmente, da noção do princípio de inércia, postulado no "Projeto para uma psicologia científica" como a tendência a livrar completamente os neurônios da quantidade de energia que recebem, isto é, a levar o mecanismo da descarga ao seu máximo, de modo que a excitação seja totalmente eliminada.

Todavia, estes dois princípios se afastam nas elaborações teóricas posteriores, quando o da inércia neurônica é substituído pelo princípio de constância, devido à constatação da necessidade de se manter constante certa quantidade de energia para o organismo executar as ações necessárias para a sua autoconservação. O princípio de constância só foi formulado como tal em 1920, no ensaio "Mais além do princípio do prazer”, mas a compreensão nele contida já se encontrava no que se denominou anteriormente "tendência para a constância”, que fazia parte, inclusive, das concepções acerca do aparelho psíquico organizadas por Freud e Breuer por volta dos anos 1892-1895. Dessa forma, inicialmente se propôs a existência de uma tendência para a constância como uma função secundária ao princípio de inércia, tendência essa que foi imposta pelas exigências da vida:

"A tendência do sistema nervoso, mantida durante todas as modificações, é a de evitar que fique carregado de Qn ou a reduzir a carga ao mínimo possível. Sob a pressão das exigências da vida, o sistema nervoso se viu forçado a guardar uma reserva de Qn.” (FREUD, 1895/1990, p.345)

O sistema nervoso foi forçado a guardar uma reserva de quantidade energética, pois, caso houvesse a eliminação total da excitação, como postulava o princípio de inércia, o organismo morreria. O princípio de constância, além de visar à diminuição da carga de excitação, garante também que um mínimo de energia se mantenha constante. Constitui, por um lado, uma defesa contra o aumento energético; por outro, porém, não permite o escoamento total, mantendo constante certa quantidade de energia por meio do evitamento dos estímulos externos e descarga dos estímulos internos.

Desse modo, observamos como desde o início Freud preocupava-se com a regulação vital do psiquismo, sendo o excesso de estímulo experimentado como algo incômodo e perturbador que precisa ser eliminado. O aparelho psíquico apresentado em 1895 consiste em um sistema de regulação das quantidades que o atingem, de modo a que possa haver uma regulação que conduza ao prazer e à satisfação. Esses são resultado da descarga energética, sendo essa última a função por excelência do aparelho. 
Assim, podemos dizer que o esquema de 1895 inscreve-se no modelo da descarga, concebendo o psiquismo como um aparelho de captura das intensidades. A função do aparelho será, já nesse momento, a de conduzir a quantidade de energia através dos caminhos possíveis de serem percorridos, ou seja, pelos trilhamentos e facilitações que abrem vias de acesso para a passagem da excitação. O trilhamento que cada aparelho estabelece deixará marcas individuais, constituindo, a nosso ver, a singularidade de cada um. O aparelho, já neste momento inicial da teoria, se apresenta como tendo a tarefa de encontrar destinos psíquicos para a intensidade pulsional. Assim, vemos como desde os primórdios da teoria freudiana o excesso é a marca da pulsão, e esta possui, em seu cerne, a força motriz que conduz ao trabalho de escoamento.

Portanto, é nesse sentido que propomos pensar uma similitude entre a dilapidação em Bataille e o ponto de vista econômico em Freud. Há neste último também uma espécie de princípio da perda equivalente ao detectado por Bataille como característica inerente aos organismos vivos, ocasionado pelo excesso pulsional e a necessidade de seu escoamento. Obviamente marcando as diferenças que existem entre os dois autores, pensamos que o modelo exposto por Bataille para a compreensão dos sistemas, sejam eles individuais ou coletivos, é semelhante ao que Freud propõe para a sua concepção de psiquismo.

Em ambos os autores encontramos a ideia de que há uma pressão permanente provinda de um excesso que perturba os organismos vivos, havendo então a exigência da despesa, do gasto ou da descarga. No caso da psicanálise, esse dispêndio ocorre sob a forma da dominação dos estímulos, principal função do aparelho psíquico, realizada por meio da descarga energética ou pela elaboração psíquica.

Recebido em 15/2/2010. Aprovado em 5/4/2010.

\section{REFERÊNCIAS}

BATAiLlE, G. (1933/1975) “A noção de despesa”, in A parte maldita. Rio de Janeiro: Imago. (1949/1975) A parte maldita. Rio de Janeiro: Imago. (1957/1980) O erotismo. Lisboa: Moraes editores.

BIRMAN, J. (2009). As pulsões e seus destinos: do corporal ao psíquico. Rio de Janeiro: Civilização Brasileira.

DAVID-MÉNARD, M. (2000) Tout le plaisir est pour moi. Paris: Hachette.

FREUD, S. (1974-1976) Edição standard brasileira das obras psicológicas completas. Rio de Janeiro: Imago.

(1895) “Projeto para uma psicologia científica”, v.I, p.381-456.

(1915) "Os instintos e suas vicissitudes”, v.XIV, p.123-162.

(1920) “Além do princípio do prazer”, v.XVIII, p.13-88. 
GODELIER, M. (2001) O enigma do dom. Rio de Janeiro: Civilização Brasileira.

MAUSS, M. (1924/1950) “Essai sur le don. Forme et raison de l'échange dans les sociétés archaïques”, in Sociologie et anthropologie. Paris: PUF.

CAILlÉ, A. (1998) "Nem holismo nem individualismo metodológicos. Marcel Mauss e o paradigma da dádiva”, in Revista Brasileira de Ciências Sociais, v.13, n.38, São Paulo, Anpocs, p.5-38.

Isabel Fortes

mariaisabelfortes@gmail.com 